\title{
A CIDADE SOB A ÓTICA DE QUEM VIVE NA ESCURIDÃO
}

\author{
THE CITY IN THE PERSPECTIVE OF WHO LIVES IN DARKNESS
}

Recebido em 14.03.2013. Aprovado em 09.09.2013

Avaliado pelo sistema double blind review

DOI:http://dx.doi.org/10.12712/rpca.v7i3.265

\begin{abstract}
Armando Araújo de Souza Júnior
armando-jr07@bol.com.br

Departamento de Administração - Universidade Federal do Amazonas (UFAM) - Manaus AM - Brasil.
\end{abstract}

Ana Flávia de Moraes Moraes

anaflaviademoraesmoraes@gmail.com

Departamento de Administração - Universidade Federal do Amazonas (UFAM) - Manaus AM - Brasil.

\section{Resumo}

Este artigo apresenta um estudo sobre a percepção dos deficientes visuais sobre as condições de acessibilidade na cidade de Manaus. 0 direito a acessibilidade é assegurado pela Constituição da República Federativa do Brasil e é regulamentado por um grande aparato de Leis Federais, Estaduais e Municipais. Uma pessoa que nasceu sem a visão ou que a perdeu no decorrer de sua vida utiliza os demais sentidos: olfação, audição e tato para se inteirar com o mundo, sendo o tato, o principal deles. Uma vez bem desenvolvido, o deficiente visual pode perfeitamente identificar formas, pessoas, objetos e realizar as mais diversas atividades tanto domésticas quanto profissionais. A estratégia de pesquisa utilizada foi à pesquisa qualitativa, de cunho descritivo, baseada em entrevistas semiestruturadas, realizadas junto a seis deficientes visuais residentes na cidade de Manaus. 0 conteúdo das entrevistas foi tratado por meio da análise do conteúdo. Os dados coletados foram analisados e o conteúdo permitiu expressar os fenômenos estudados e a relação entre o que a Legislação Brasileira prevê e o que de fato é cumprido. Foi possível evidenciar que as condições de acessibilidade para as pessoas com deficiências visuais em espaços públicos e privados não atende os requisitos previstos em lei.

Palavras-chaves: Cidades. Acessibilidade. Deficientes visuais.

\begin{abstract}
This study presents an overview and reflects about the topic 'new organizational forms', This paper presents a study on the perception of the visually impaired on the accessibility conditions in the city of Manaus. The right accessibility is guaranteed by the Constitution of the Federative Republic of Brazil and is regulated by a large apparatus of Federal Laws, State and Municipal. A person who was born without sight or lost in the course of his life uses the other senses: smell, hearing and touch to get acquainted with the world, and touch, the main one. Once successfully developed, the visually handicapped can perfectly identify shapes, people, objects and perform various activities both domestic and professional. The search strategy used was the qualitative research, a descriptive, based on semi-structured interviews, conducted with six visually impaired residents in the city of Manaus, the contents of the interviews were treated by the analysis of discourse. The collected data were analyzed and the contents allowed to express the phenomena studied and the relationship between the Brazilian laws provides and what is actually done. The results showed that the conditions of accessibility for people with visual disabilities in public and private spaces does not meet the requirements provided by law.
\end{abstract}

Keywords: Cities. Acessibility. Visually impaired. 


\section{Introdução}

O objetivo deste artigo é descrever a percepção dos deficientes visuais sobre as condições de acessibilidade na cidade de Manaus. 0 interesse pelo tema se deve à observação dos dados publicados pelo Instituto Brasileiro de Geografia e Estatística (IBGE) no ano de 2010 onde mais de 45 milhões de brasileiros declararam possuir algum tipo de deficiência de acordo com os dados do Censo Demográfico do ano de 2010, número este que representa aproximadamente $23 \%$ da população brasileira. Desse total, 35,7 milhões de pessoas responderam que possuem alguma dificuldade para enxergar mesmo utilizando óculos ou lentes de contato, sendo que, mais de 506 mil pessoas informaram serem cegas.

Na Declaração Universal dos Direitos Humanos e nos Pactos Internacionais de 2008, através das Nações Unidas, proclamou-se e concordou-se que toda pessoa faz jus aos direitos e liberdades ali estabelecidos, sem distinção de qualquer espécie reafirmando a universalidade, a indivisibilidade, a interdependência e a interrelação dos direitos humanos e liberdades fundamentais, bem como a necessidade de que todas as pessoas com deficiência tenham a garantia de poder desfrutá-los plenamente, sem discriminação (MINISTÉRIO DA JUSTIÇA, 2008).

A Constituição Federal de 1988 em seu Capítulo VII, art. 227 prevê "a facilitação do acesso aos bens e serviços coletivos, com a eliminação de preconceitos e obstáculos arquitetônicos", determina ainda, em seu parágrafo segundo que "a lei disporá sobre normas de construção dos logradouros e dos edifícios de uso público e de fabricação de veículos de transporte coletivo, a fim de garantir acesso adequado as pessoas com deficiências". No Capítulo IX do art. 244, dispõem sobre a "adaptação dos logradouros, dos edifícios de uso público e dos veículos de transporte coletivo atualmente existentes a fim de garantir acesso adequado às pessoas com deficiência" (CONSTITUIÇÃO FEDERAL, 1988).

Considerando esses dois pressupostos legais, a pessoa com deficiência visual tem o direito de acesso e deve ter a garantia de que estes acessos sejam assegurados autonomamente. Para ratificar este direito a Lei Federal no 10.098 de 19 de dezembro de 2000, Lei da acessibilidade, estabelece, ainda, normas gerais e critérios básicos para a promoção da acessibilidade das pessoas com deficiência ou com mobilidade reduzida.

Evidencia-se a importância da questão da acessibilidade para pessoas com deficiências no Brasil tendo em vista a necessidade de adaptação das cidades para proporcionar acessibilidade e inclusão social para esta parcela da população. Para Cambiachi (2007), um espaço adequado e acessível, as atividades de uma pessoa com deficiência são preservadas, e a deficiência não afeta as suas funções.

0 tema também vem sendo alvo de pesquisas acadêmicas. Trabalhos recentes como os de Chagas (2006), Person (2006), Caselli (2007), Nascimento (2007), Blanco (2007), Linhares (2008), Morais (2008) e Campos (2008) pesquisaram diferentes perspectivas sobre o tema acessibilidade e em diferentes contextos. Em comum nos trabalhos pesquisados, a preocupação com a inclusão social das pessoas com deficiências e a constatação de que o Brasil e as cidades brasileiras precisam avançar na difusão do conhecimento sobre a questão das pessoas com deficiências, da inclusão social e da acessibilidade para a promoção plena da igualdade entre as pessoas.

Este artigo está estruturado em 6 seções, além desta Introdução que contextualiza o tema e a pesquisa desenvolvida. Como segunda seção, tem-se o referencial teórico que foi elaborado com o intuito de caracterizar conceitos e legislações aplicáveis ao tema objeto deste artigo. Na terceira seção tem-se a caracterização histórica e econômica do estado do Amazonas e da cidade de Manaus para melhor compreensão do contexto de realização da pesquisa. Na quarta seção 
tem-se o detalhamento da metodologia de realização da pesquisa de campo e, seguindo essa seção, os resultados da pesquisa são apresentados e analisados. Na quinta seção são tecidas considerações finais que resgatam os objetivos e resultados mapeados com a pesquisa e são propostas reflexões para estudos futuros. Finalizando a estruturação deste artigo, as referências que pautaram o desenvolvimento do referencial teórico e da pesquisa são apresentadas.

\section{Estudo da deficiência visual no âmbito do campo da Administração}

Estudos sobre pessoas com deficiência incluem-se no campo de investigações sobre a diversidade que, nos últimos anos, se vem caracterizando como tema relevante dos estudos organizacionais. Pesquisas sobre essa nova realidade são necessárias para introduzir uma lógica nas relações de trabalho: a lógica da inclusão. Essa nova lógica tem como premissa substituir a busca por um homem ideal, ou trabalhador ideal, de forma a acolher as diferenças.

Ainda que a inclusão de pessoas com deficiência mantenha as contradições próprias às relações de trabalho capitalistas, transformando as diferenças em mercadoria e em diferencial competitivo para as organizações, ela abre possibilidades para um ordenamento social menos discriminatório. E, considerando que a Administração, enquanto Ciência, discute a temática trabalho, esta pesquisa foi desenvolvida com a pretensão de se fomentar essa discussão, a partir da temática acessibilidade e como forma também de inspirar outros estudos e/ou ampliar o estudo aqui proposto.

A acessibilidade física é hoje uma necessidade básica para que todas as pessoas, independentemente de suas habilidades, possam desenvolver atividades da vida cotidiana com autonomia e mobilidade. 0 aspecto importante da acessibilidade física é ser um facilitador da inclusão das pessoas portadoras de deficiência, inclusive no mundo do trabalho. E esta inclusão não se limita à adequação à lei de cotas, por parte dos empregadores.

As organizações de trabalho deverão adequar-se para receber portadores de deficiência em seus quadros funcionais, possuindo, por exemplo, equipamentos tecnológicos adequados para os portadores de deficiência visual e elevadores e/ou plataforma para cadeirantes. Assim, o grande desafio em dar continuidade à universalização da acessibilidade está em adequar seus edifícios obedecendo à legislação vigente, eliminando as barreiras arquitetônicas e proporcionando a todos o acesso e a livre circulação.

\section{0 deficiente visual}

Os autores procuram diferenciar a deficiência visual em duas categorias. Para Mendes (2009) um deficiente visual é aquela pessoa com visão subnormal (reduzida) ou com cegueira. Amiralian (1997) caracteriza a deficiência na visão de acordo com a sua intensidade (leve, moderada, profunda, severa ou perda total).

Para Oliveira e Carvalho (2005), qualquer pessoa, sem exceção, pode nascer com a deficiência visual ou adquiri-la durante a vida. 0 autor também enfatiza que a perda da visão pode ser decorrente de um acidente ou de uma doença súbita, em alguns casos, o processo de perda da visão se dá de forma lenta, onde a pessoa atingida demora a perceber que está perdendo a visão.

Segundo Caselli (2007), um indivíduo é portador de baixa visão quando a deficiência visual interfere ou compromete a realização de atividades ou limita o seu desempenho. Uma pessoa é considerada cega quando corresponde a um dos seguintes critérios: a visão corrigida do melhor dos olhos é igual ou inferior a 20/200, ou se o diâmetro mais amplo de seu campo visual não atinge um ângulo maior do que 20 graus que caracteriza um campo visual restrito. Em termos 
pedagógicos, como cita o autor, um indivíduo cego necessita de instrução em Braille (Sistema de Escrita por Pontos em Relevo) para se comunicar e, um indivíduo com visão subnormal consegue lê tipos e impressos ampliados com ou sem o auxílio de recursos ópticos. Em síntese, a deficiência visual pode ser considerada como uma anomalia física que acarreta em dificuldades no processo de desenvolvimento dos seres humanos.

Davidoff (2001) considera a visão como o sentido humano mais importante, pois através dela o indivíduo reconhece o mundo em que vive, percebe e identifica as coisas, sem ela, fica dependente. Na ausência dela, os seres humanos são obrigados a desenvolverem os outros sentidos para poderem se desenvolver e serem inseridos na sociedade. 0 desenvolvimento do tato é fundamental para esse processo.

Para Normann (2004), assim como a LIBRAS (Língua Brasileira de Sinais) atende as pessoas com deficiência auditiva, o BRAILLE atende as pessoas com deficiência visual. 0 método foi desenvolvido por um jovem francês, cego, chamado de Louis Braille, na metade do século 1800. Atualmente, o método é consagrado e difundido em todos os continentes. Tornou-se um instrumento fundamental para romper as barreiras intelectuais e as dificuldades impostas pela deficiência visual. Segundo o autor, o método proporciona o acesso das pessoas com deficiência visual à sociedade e a sua cultura.

Oliveira e Carvalho (2005) enfatizam que a visão permite aos indivíduos o conhecimento e a interpretação do mundo, ou seja, é através dos olhos que os indivíduos captam os estímulos sensoriais que são fundamentais para as suas relações com objetos, pessoas, formas e situações da vida social.

Sem a visão, o indivíduo perde a capacidade de se relacionar com o mundo externo. Durante toda a sua existência, encontrará dificuldades das mais diversas formas e intensidades, passará a depender de sua autoconfiança e da colaboração de outros indivíduos.

A utilização dos demais sentidos torna-se uma alternativa para os deficientes visuais interagirem com o mundo externo. Para Leão (2007), os demais sentidos podem proporcionar:

a) Tato: comunicação e percepções através do contato da pele com objetos, pessoas e coisas;

b) Olfato: sentir o perfume, o aroma da comida, etc.;

c) Audição: ouvir o som produzido no ambiente;

d) Paladar: sentir o gosto das coisas.

Por meio desses sentidos, o deficiente visual pode captar diferentes sensações, além de constituírem possibilidades para a sua inclusão na sociedade.

\section{Acessibilidade}

A acessibilidade integral é a possibilidade de uso com segurança e conforto de objetos, equipamentos e ambientes de maneira independente e autônoma pelo maior número possível de indivíduos. Segundo Sarraf (2007) estar acessível não diz respeito à eliminação de barreiras físicas somente, mas do campo das informações, das atitudes. De acordo com a legislação, no artigo segundo da Lei no. 10.098 de 19 de dezembro de 2000, acessibilidade remete ao alcance para utilização, com segurança e autonomia, dos espaços, mobiliários e equipamentos urbanos, das edificações, dos transportes e dos sistemas e meios de comunicação, por pessoa com deficiência ou com mobilidade reduzida. 
Acessibilidade diz respeito a locais, produtos, serviços ou informações efetivamente disponíveis ao maior número e variedade possível de pessoas independente de suas capacidades físico-motoras e perceptivas, culturais e sociais. Isto requer a eliminação de barreiras arquitetônicas, a disponibilidade de comunicação, de acesso físico, de equipamentos e programas adequados, de conteúdo e apresentação da informação em formatos alternativos. (BRASIL, 2008, p.256).

Para Bernardi e Kowaltowski (2005), a acessibilidade de um espaço está relacionada a eliminação das barreiras físicas e atitudinais. Para que isto seja possível, os autores argumentam que o desenho do espaço deve se estender a uma ampla diversidade de usuários para que os mesmos possam interagir com o ambiente. Morais (2007) defende que a funcionalidade de um espaço é realçada quando as barreiras físicas são removidas. Os autores compartilham a idéia de que o desenho dos espaços é uma condição necessária para promover a acessibilidade e está fundamentada em sete princípios: (1) Uso equitativo; (2) Uso flexível; (3) Uso simples e intuitivo; (4) Informação de fácil percepção; (5) Tolerância ao erro; (6) Mínimo esforço físico e; (7) Dimensão e espaço para aproximação e uso.

A Associação Brasileira de Nomas técnicas (ABNT), através do Fórum Nacional de Normatização, constituiu a NBR 9050:2004 - Acessibilidade a Edificações, Mobiliário, Espaços e Equipamentos Urbanos. Esta norma estabelece critérios e parâmetros técnicos quanto a projetos, construções, instalações e adaptações em edificações, mobiliário, espaços e equipamentos urbanos a fim de normatizar os critérios e parâmetros técnicos sobre as condições de acessibilidade. Diversas condições de mobilidade e de percepção do ambiente foram consideradas, com ou sem a ajuda de aparelhos específicos, como: próteses, aparelhos de apoio, cadeiras de rodas, bengalas de rastreamento, sistemas assistivos de audição ou qualquer outro que venha a complementar as necessidades individuais das pessoas.

A ABNT 9050:2004 define que, independentemente de idade, estatura, limitação de mobilidade ou percepção, esta Norma visa proporcionar à maior quantidade possível de pessoas, a utilização de maneira autônoma e segura do ambiente. Todos os espaços, edificações, mobiliário e equipamentos urbanos que vierem a ser projetados, construídos, montados ou implantados, bem como as reformas e ampliações, devem atender ao disposto para serem considerados acessíveis.

De acordo com a NBR 9050:2004 os espaços devem evitar ou minimizar as barreiras físicas em ambientes internos e externos para os deficientes visuais. 0 quadro abaixo apresenta as principais recomendações da norma para garantir a acessibilidade dos deficientes visuais. 
Quadro 1 - Síntese da Legislação Federal sobre Acessibilidade

\begin{tabular}{|c|c|}
\hline Item & Breve Descrição \\
\hline Calçadas & $\begin{array}{l}0 \text { ideal é que o piso seja o mais regular possível, sem desníveis e } \\
\text { antiderrapante. }\end{array}$ \\
\hline $\begin{array}{l}\text { Mobiliário } \\
\text { Urbano }\end{array}$ & $\begin{array}{l}\text { A colocação de mobiliários urbanos nas esquinas devem ser evitados para } \\
\text { facilitar a locomoção dos deficientes visuais bem como a visibilidade dos } \\
\text { motoristas que trafegam pelas vias. O ideal seria que o piso das vias fosse } \\
\text { adaptado e possuíssem uma textura diferenciada para indicar a presença de } \\
\text { orelhões e caixas de correio, por exemplo. }\end{array}$ \\
\hline Linha Guia & $\begin{array}{l}\text { É recomendada a sua instalação ao longo de muros ou passeios e em terrenos } \\
\text { baldios e com desníveis. Essa linha informa o deficiente visual o caminho a ser } \\
\text { seguido. }\end{array}$ \\
\hline $\begin{array}{ll}\text { Guia } & \text { de } \\
\text { Balizamento }\end{array}$ & $\begin{array}{l}\text { Deve ser instalado junto aos limites laterais das superfícies de piso com vistas a } \\
\text { definir claramente os limites de circulação e perceptíveis por pessoas com } \\
\text { deficiência visual. }\end{array}$ \\
\hline Piso Tátil & $\begin{array}{l}\text { Piso caracterizado pela diferenciação de textura em relação ao piso do espaço, } \\
\text { serve de alerta ou de linha guia. }\end{array}$ \\
\hline $\begin{array}{l}\text { Marcações e } \\
\text { Mapas em Braille }\end{array}$ & $\begin{array}{l}\text { Devem ser dispostos nos espaços públicos para auxiliar a identificação dos } \\
\text { locais. }\end{array}$ \\
\hline $\begin{array}{l}\text { Sinalização } \\
\text { Sonora }\end{array}$ & $\begin{array}{l}\text { Recomenda-se a instalação desses equipamentos na saída de garagens e } \\
\text { estacionamentos para informar a passagem de veículos automotores. }\end{array}$ \\
\hline Ruas & $\begin{array}{l}\text { Devem estar conservadas, sem buracos, bueiros sem tampa, sem pedras soltas } \\
\text { ou outras barreiras que possam colocar em risco a integridade física do } \\
\text { deficiente visual. Nos cruzamentos, recomenda-se a instalação de sinalizadores } \\
\text { táteis. }\end{array}$ \\
\hline $\begin{array}{l}\text { Faixa } \\
\text { Segurança }\end{array}$ & $\begin{array}{l}\text { Recomenda-se que estejam revestidas com material áspero, para que possam } \\
\text { ser identificadas pelos deficientes visuais. }\end{array}$ \\
\hline Semáforos & $\begin{array}{l}\text { Recomenda-se que sejam equipados com sinalizadores sonoros que informem } \\
\text { ao deficiente visual que podem atravessar a via. }\end{array}$ \\
\hline Escadas & $\begin{array}{l}\text { Não devem ter degraus vazados ou com beiras salientes e sim arredondadas, } \\
\text { antiderrapantes e com Linhas Guias instaladas. }\end{array}$ \\
\hline Elevadores & Painel de controle deve ser representado em caracteres Braille. \\
\hline $\begin{array}{l}\text { Veículos } \\
\text { transporte }\end{array}$ & $\begin{array}{l}\text { Devem ter assentos preferenciais e próximos às portas de acesso, dotados de } \\
\text { sinais sonoros e avisos em caracteres Braille. }\end{array}$ \\
\hline
\end{tabular}

Fonte: Elaborado pelos autores da pesquisa a partir da NBR 9050:2004, 2012.

No entanto, como cita Carvalho (2003), o deficiente visual além das lutas pelo direito a acessibilidade nos espaços, também é excluído de muitas oportunidades, como o acesso a educação, por exemplo. Barros e Costa (2006) citam que o uso da tecnologia como os sintetizadores de voz e as impressoras Braille contribuem para o processo de inserção social dos deficientes visuais, porém, reconhece que existem muitas lacunas que precisam ser preenchidas. Os autores alertam para o fato de que uma parcela significativa dos deficientes visuais vivem na sociedade em regiões de baixo poder aquisitivo e muitas das vezes, não tem acesso a educação e nem tão pouco aos aparatos tecnológicos modernos adaptados a esse tipo de deficiência.

Borges (1996) defende a tese de que os deficientes visuais poderiam ser mais produtivos se tivesse acesso à educação profissionalizante adaptada. Também reforça que a probabilidade de uma criança deficiente visual seja quatro vezes maior de não ser alfabetizada, principalmente pela carência de escolas com profissionais capacitados para esse tipo de educação.

Para Oliveira e Carvalho (2005), o preconceito gerado pelas pessoas ditas normais é considerado como o grande responsável pela exclusão e marginalização dos deficientes visuais. 
A família segundo Rosadas (1994) possui um papel fundamental no que se refere à inclusão social, contribui diretamente para a aceitação dos deficientes na sociedade e na própria família.

Além dos aspectos legais para promover a acessibilidade das pessoas com deficiência visual, os estudos acadêmicos mostram a necessidade e a importância de promover o acesso pleno dessas pessoas, não só aos espaços, mas, principalmente, a cidadania.

\section{A legislação brasileira}

A Constituição Federal de 1988 assegura que todos devem ter equidade de direitos e acessibilidade: à educação, à saúde, ao trabalho, ao lazer, à previdência social, ao amparo, à infância e à maternidade, dignidade e a não discriminação. No capítulo VII, são estabelecidas garantias para criação de programas de prevenção e atendimento especializado para pessoas com deficiência física, sensorial ou mental.

Já no artigo 21, o Poder Público, por meio dos organismos de apoio à pesquisa e das agências de financiamento, disponibiliza-se a fomentar programas destinados à promoção de pesquisas científicas voltadas ao tratamento e prevenção de deficiências, ao desenvolvimento tecnológico orientado à produção de ajudas técnicas para as pessoas portadoras de deficiência e à especialização de recursos humanos em acessibilidade.

Em seu artigo 203, a Constituição Federal define que é competência da União, Estados e do Distrito Federal a habilitação ou reabilitação das pessoas portadoras de deficiência bem como promover a sua integração à vida social.

Em dezembro de 1999, através do Decreto no 3.298 - DOU de 21/12/99, foi regulamentada, por meio da Lei no 7.853, de 24 de outubro de 1989, a consolidação das normas de proteção e outras providências sobre a Política Nacional para a Integração da Pessoa Portadora de Deficiência.

De acordo com a legislação, a Lei no 10.098, de 19 de dezembro de 2000, conhecida como Lei de Acessibilidade, em seu Capítulo VII (da acessibilidade nos sistemas de comunicação e sinalização), artigo 18, dispõe que: “O Poder Público implementará a formação de profissionais intérpretes de escrita em braile, língua de sinais e de guias-intérpretes, para facilitar qualquer tipo de comunicação direta à pessoa portadora de deficiência sensorial e com dificuldade de comunicação". O quadro abaixo sintetiza as diversas leis federais que regulamentam a acessibilidade das pessoas com deficiência. 
Quadro 2 - Síntese da Legislação Federal sobre Acessibilidade

\begin{tabular}{|l|l|}
\hline \multicolumn{1}{|c|}{ Lei } & \multicolumn{1}{c|}{ Síntese } \\
\hline Lei No 7.405/85 & $\begin{array}{l}\text { Torna obrigatória a colocação do “Símbolo Internacional de Acesso" em todos } \\
\text { os espaços que permitam a sua utilização por pessoas com deficiência. }\end{array}$ \\
\hline Lei No $7.853 / 89$ & $\begin{array}{l}\text { Dispõem sobre o apoio e a integração social das pessoas com deficiência, sobre } \\
\text { a Coordenadoria para Integração da Pessoa Portadora de Deficiência. }\end{array}$ \\
\hline Lei No $8.899 / 94$ & $\begin{array}{l}\text { Estabelece o direto ao passe livre às pessoas com deficiência no sistema de } \\
\text { transporte interestadual. }\end{array}$ \\
\hline Lei No 10.048/00 & Dispõem sobre a prioridade de atendimento das pessoas com deficiência. \\
\hline Lei No 10.089/00 & Lei da Acessibilidade \\
\hline Lei No 10.226/01 & $\begin{array}{l}\text { Normatiza a escolha dos locais de votação de acesso mais fácil para o eleitor } \\
\text { com deficiência. }\end{array}$ \\
\hline Lei No 11.126/05 & $\begin{array}{l}\text { Regulamenta o direito do deficiente visual de ingressar e permanecer em } \\
\text { espaços coletivos acompanhados de cão-guia. }\end{array}$ \\
\hline
\end{tabular}

Fonte: Elaborado pelos autores da pesquisa, 2012.

Além da própria Constituição Federal, Estados e Municípios tem avançado na elaboração de leis que assegurem o direito das pessoas com deficiências, ficando o Poder Executivo responsável pela viabilização, aplicação e fiscalização do cumprimento dessas leis.

\section{Contextualização histórica e econômica do lócus da pesquisa}

O Amazonas é uma das 27 unidades federativas do Brasil, sendo a maior delas em território, com uma área de 1.570.745, $680 \mathrm{~km} 2$. Pertencente à Região Norte do Brasil, é a segunda unidade federativa mais populosa, com seus 3,6 milhões de habitantes em 2012. No entanto, apenas dois de seus 62 municípios possuem população acima de 100 mil habitantes: Manaus, a capital e sua maior cidade com 1,8 milhão de habitantes em 2012, que concentra cerca de $60 \%$ da população do estado, e Parintins, com quase 104 mil habitantes (CENSO, 2012).

0 que caracteriza esse imenso território são fatores que dificultam ações de desenvolvimento regional, tais como: baixa densidade demográfica, economia estagnada, grandes distâncias da capital, difícil acesso, precária infraestrutura e baixa capacidade de atração de investimentos, dentre outros fatores, mesmo sendo possuidor de grandes potenciais econômicos (AMAZONAS, 2010).

O estado possui um dos mais baixos índices de densidade demográfica no país, superior apenas ao estado de Roraima. Conforme dados do Instituto Brasileiro de Geografia e Estatística (IBGE), a densidade demográfica equivale a 2,23 habitantes por quilômetro quadrado. Possui o maior Índice de Desenvolvimento Humano (IDH), cerca de 0,774, e o maior PIB per capita entre todos os estados do Norte do Brasil (CENSO, 2012).

Manaus, capital estado do Amazonas é o principal centro financeiro, corporativo e econômico da região norte do Brasil. A implantação do Projeto Zona Franca de Manaus, resultado de clara inspiração geopolítica, foi uma das estratégias de ocupação da Amazônia brasileira, região de baixa densidade demográfica, em 28 de fevereiro de 1967. Com isso foi institucionalizada a Zona Franca de Manaus (ZFM), proporcionando condições para o surgimento de um importante centro industrial, comercial e agropecuário no Estado do Amazonas.

Considerada a mais bem sucedida experiência brasileira, no campo do desenvolvimento econômico regional, o Projeto ZFM, atua como fator de preservação da Floresta Tropical Úmida, no Amazonas, mantendo-a preservada por cerca de $98 \%$ de sua cobertura florestal, exatamente pelo modelo exógeno que pouco se relaciona com a base local de recursos naturais existentes nos delicados ecossistemas da Floresta Amazônica (AMAZONAS, 2010). 
A área de abrangência da ZFM, em Manaus, foi estabelecida em $10.000 \mathrm{Km} 2$, compondo-se de um Distrito Industrial, um Distrito Agropecuário e uma Zona de Livre Comércio, que oferece benefícios fiscais e outras vantagens competitivas atraentes a novos investidores (GARCIA, 2004).

Passados 45 anos de sua criação, a ZFM, mantém hoje um setor industrial bem consolidado e tecnologicamente avançado. Possui também um setor comercial que continua em franca expansão, comercializando larga variedade de artigos eletroeletrônicos, perfumaria, vestuário, informática, entre outros. Os principais investimentos econômicos se encontram nos Setores Secundário e Terciário.

\section{Procedimentos metodológicos}

Essa pesquisa se baseia em uma abordagem qualitativa para descrever a percepção dos deficientes visuais sobre as condições de acessibilidade na cidade de Manaus. Para Denzin e Lincoln (2006), a pesquisa qualitativa é um campo de investigação que atravessa disciplinas, campos e temas. Em torno da pesquisa qualitativa, pode ser encontrada uma família interligada e complexa de termos, conceitos e suposições de diversas fases da história da ciência moderna.

Trata-se de um estudo descritivo cujo instrumento de coleta de dados foi uma entrevista com roteiro semiestruturado efetuada junto a seis pessoas com deficiência visual moradores da cidade de Manaus. Os entrevistados foram informados do real objetivo da pesquisa e tiveram o anonimato e a confidencialidade de seus relatos garantidos através da assinatura de um Termo de Consentimento. Os entrevistados foram codificados de E1 a E6.

Para Cooper e Schindler (2003), um estudo descritivo tem por objetivo descrever as características de determinada população ou fenômeno e, concomitantemente, preocupa-se em identificar fatores que possam determinar ou que contribuam para a ocorrência de determinado fenômeno.

A entrevista segundo Rey (2005) permite um diálogo entre o pesquisador e o sujeito da pesquisa. As conversações geram uma co-responsabilidade devido a cada um dos participantes se sentirem sujeitos do processo, facilitando a expressão de cada um por meio de suas necessidades e interesses. Nesse processo, cada participante atua de forma reflexiva, ouvindo e elaborando hipóteses por intermédio de posições assumidas por ele sobre o tema de que se ocupa. Segundo este autor, o pesquisador, diante de cada resposta, pode reagir de várias formas, dependendo da sua criatividade e de seus objetivos na pesquisa. Já para Thiollent (1997), uma entrevista com roteiro semi-estruturado, deve conter um pequeno número de perguntas abertas relacionadas com os problemas que foram julgados prioritários pelo pesquisador.

As entrevistas foram realizadas nos dias 3 e 4 do mês de dezembro de 2012 e tiveram uma duração média de 15 minutos. Os dados coletados durante a realização das entrevistas foram gravados e depois transcritos. Para análise e interpretação dos dados, foi utilizada a análise do conteúdo (Rodrigues e Leopardi, 1999; Bauer, 2002; Vala, 2003; BARDIN, 2004).

\section{Resultados da pesquisa}

A perda ou a ausência da visão representa uma espécie de castigo para os deficientes visuais, viver na escuridão retrata uma trajetória de sofrimento, rejeição, perdas e de exclusão social. Os significados dessa trajetória estão representados nos fragmentos de discurso de E1, E3, E4 e E6. 
(E1) Para quem já enxergou ser cego é o fim do posso. Até os dezesseis anos tinha uma vida normal até que um acidente de carro transformou a minha vida. Deixei de estudar, perdi a namorada e senti na pele o que é o preconceito, inclusive na própria família.

(E3) Eu já nasci cego. Quando eu era criança, as outras crianças me tratavam como um algo diferente. Como eu poderia brincar se não conseguia enxergar, sentia-me excluído.

(E4) Já escutei muitas coisas desagradáveis em minha vida. Já me decepcionei muitas vezes, inclusive com pessoas de minha família. Não existe nada pior do que o preconceito. Os problemas que enfrento diariamente para me locomover até o trabalho, para passear são bem menores do que a discriminação e o preconceito.

(E6) Fiquei cego quando ainda era criança. Nasci com uma má formação de alguns órgãos: rins, coração e problemas ósseos. A cegueira foi uma complicação desses problemas. Minha vida foi sempre um oceano de problemas. Porém, o maior deles é rejeição por parte das pessoas, são muito preconceituosas. Essa é uma dor insuportável.

A sequencia das seleções lexicais "senti na pele o que é preconceito", "sentia-me excluído", "já escutei muitas coisas desagradáveis em minha vida" e "são muito preconceituosas" reforçam o sentimento de exclusão dos deficientes visuais. Além de ter que conviver com a deficiência, a pessoa vê-se relegada às oportunidades de que dispõem. Os deficientes visuais são vítimas de vários tipos de estereótipos e discriminação, são rotulados como pessoas que não possuem as características do padrão normal exigido pela sociedade.

As dificuldades estão por todos os lugares. As edificações, as vias públicas, os passeios, enfim, a própria cidade não está preparada para acolher essa parcela da população. A deficiência também impõe uma sentença, sair de casa representa um risco para a integridade física desses indivíduos. Os fragmentos de discurso de E2, E4 e E5 retratam essa realidade.

(E2) A cidade e os prédios não foram construídos para quem possui algum tipo de deficiência, principalmente os cegos. As ruas são esburacadas, as calçadas cheias de desníveis, fica complicado sair de casa. Se não for acompanhado, nem tento sair. Já sofri muitas quedas.

(E4) É só olhar o caminho para chegar até aqui. Sempre é um desafio. Felizmente, tenho minha esposa que me acompanha. Sem ela, seria impossível me locomover na cidade.

(E5) Eu já quebrei a perna e o braço em duas ocasiões. A perna eu cai em um buraco - fiquei quatro meses internado no Hospital 28 de Agosto. Dois anos depois, tropecei em uma calçada e ao cair coloquei todo o peso do corpo em cima do braço. É um perigo andar sozinho nesta cidade.

A maioria das cidades brasileiras não possui condições de acessibilidade satisfatórias e capazes de atender as necessidades dos deficientes. Fica evidente que essa questão precisa ser repensada, principalmente pelos dados recentes que apontam uma parcela significativa da população brasileira possuir algum tipo de deficiência. A partir dessa reflexão, a concepção das edificações e dos espaços deve possibilitar a inclusão, o acesso, a satisfação e o conforto dessas 
pessoas nesses ambientes. Os fragmentos de discurso E1 e E4 evidenciam a falta dessas condições de acessibilidade na cidade de Manaus. Por outro lado, o discurso de E6 ilustra outra realidade.

(E1) Dificilmente você encontra um prédio que atenda a questão da acessibilidade, inclusive os públicos. Nenhuma rua ou avenida da cidade de Manaus possui Piso Tátil, Marcações ou Sinalização Sonora.

(E4) 0 Braille só é usado nos elevadores. Não existe sinalização na cidade. A maioria dos prédios não são adaptados.

(E6) Em função de meus problemas, tive que viajar uma vez para os Estados Unidos para me tratar. Fiquei quase um mês na cidade de Boston. Em função do tratamento, não tive muitas oportunidades de sair e sentir a cidade. Porém, as poucas vezes que saí, sempre acompanhado de meu irmão e minha mãe, percebi claramente as diferenças. Tive a sensação de que aquela cidade foi construída para as pessoas deficientes.

O descumprimento da legislação e das normas técnicas, seja por negligência dos projetos de edificações e dos espaços da cidade, seja pelas deficiências da fiscalização, os deficientes visuais são excluídos. São prejudicados de exercer o seu direito de ir e vir, pois a visão é o sentido mais utilizado para a locomoção, obter informações e identificar os espaços como um todo.

Se andar pelos espaços já é um desafio, a situação se agrava para os deficientes visuais quando o assunto é circular pelas vias públicas. A cidade de Manaus vive um caos no trânsito. As intervenções que foram realizadas nos últimos anos não conseguiram atenuar o problema da mobilidade urbana na cidade.

0 desrespeito às leis de trânsito e a falta de sensibilização dos condutores apresentam-se como mais um risco integridade física dos deficientes visuais. Os acidentes e atropelamentos são comuns na cidade. A fiscalização é quase que inexistente, não consegue inibir as barbáries verificadas no trânsito da cidade. 0 poder público utiliza um falso discurso de que as coisas estão melhorando no trânsito. Os discursos de E3 e E5 retratam essa problemática.

(E3) 0 trânsito da cidade é infernal. Parece que as pessoas perderam a noção do que é certo e do que é errado. Quando saio na rua com minha mãe, é difícil atravessar uma rua até mesmo na faixa. Escuto no rádio e na televisão um comercial educativo dizendo que a cidade está mais solidária e educada quanto à questão do trânsito. Quem elaborou esse comercial precisa andar nas ruas.

(E5) A maioria dos motoristas não respeita as leis de trânsito. Atravessar na faixa é um risco para uma pessoa normal. Imagina para quem não enxerga.

Embora a cidade de Manaus esteja localizada no coração da maior floresta do planeta, a cidade possui poucos parques e áreas verdes para a prática de atividades físicas ou culturais. As opções de lazer nos espaços públicos são poucas conforme observado nos fragmentos de discurso de E2. Uma boa opção é o Centro Histórico da cidade. No entanto, para quem mora em áreas afastadas do centro da cidade, chegar lá exige um esforço adicional por parte dos deficientes 
visuais conforme relato de E4.

(E2) Não existem muitas opções de lazer na cidade. Tenho vontade de me divertir e de passear, porém, como falei anteriormente, só saio de casa se for acompanhado.

(E4) Gosto de ir ao cinema, porém, só assisto filme nacional, pois consigo entender a história do filme. Minha esposa é uma benção, é difícil sair de casa e enfrentar essa cidade maluca. Nos finais de semana, costumo freqüentar o Largo São Sebastião ao lado do Teatro Amazonas. O local é agradável, porém, chegar lá é uma complicação só.

(E5) Com todas essas coisas que já me aconteceram, sinceramente, estou evitando sair de casa. Tenho muito medo. Não quero ficar novamente em um hospital internado.

Para quem já sofreu acidentes, é uma questão a ser pensada. 0 discurso de E5 representa a sua insatisfação com os espaços públicos, prefere o isolamento em detrimento de sua diversão.

O crescimento desordenado da cidade de Manaus não veio acompanhado de ações e intervenções para possibilitar o acesso efetivo dos deficientes aos espaços públicos. A cidade percebida não foi pensada para todos. 0 discurso de E1 aponta para essa exclusão. Para E6, a impunidade é um agravante, falta fiscalização.

(E1) A cidade cresceu muito, ficou muito mais agitada. Infelizmente, parece que os governantes esqueceram dos deficientes visuais.

(E6) A cidade não é acessível em todos os aspectos. Se você não estiver acompanhado o risco é muito grande de sofrer um acidente. A legislação não é cumprida. Falta fiscalização. Tenho o direito de ir e vir. É muita impunidade.

A Lei estabelece que o Poder Público é o responsável por garantir o direito de acesso adequado aos espaços urbanos e as edificações. A legislação é vasta e, caso fosse executada em sua plenitude, as pessoas com deficiências, especialmente em seu cotidiano, poderiam se projetar de forma a prestar a sua contribuição para a sociedade. O cumprimento da legislação leva a cidadania plena, independentemente das condições sociais, físicas ou financeiras dos indivíduos.

0 direito a educação também é assegurado a todos os cidadãos. Observa-se que a inclusão educacional dos deficientes visuais é condicionada a sua capacidade financeira (conforme observado no fragmento de discurso de E6). 0 sistema educacional brasileiro vem sendo alvo de críticas das mais diversas naturezas. É reconhecido que a Educação no Brasil deve ser melhorada. No caso dos deficientes visuais, as dificuldades de acesso a educação são agravadas, as escolas públicas, em sua grande maioria não possui uma infraestrutura adequada, faltam profissionais especializados, o material didático em Braille é menor do que a demanda, dentre outras limitações.

0 acesso à educação abre um leque de oportunidades, proporciona inclusão social, possibilita uma melhor qualidade de vida, acesso ao conhecimento e, abre caminho para que o deficiente visual possa concorrer a uma vaga no mercado de trabalho. 
Quando a escola não está preparada para receber um deficiente visual, as conseqüências podem ser danosas conforme observado nos fragmentos de discurso de E4.

(E4) Meu maior sonho era cursar uma faculdade. Infelizmente, não cheguei não a concluir o ensino fundamental. A escola onde eu estudava não tinha condições de me receber. Tive que parar.

(E6) Mesmo com todos os meus problemas, consegui concluir o ensino médio. Estudei em um colégio particular que atende pessoas com deficiência visual. Graças a Deus, minha família possui uma boa condição financeira. Meu sonho agora é cursar Pedagogia.

Há de se reconhecer os avanços que o Estado Brasileiro conseguiu alcançar na formulação de Leis tem contribuído para promover a acessibilidade dos deficientes. No caso específico da cidade de Manaus, as edificações e os espaços públicos como evidenciado nas entrevistas, não estão preparados para acolher e receber os deficientes. A legislação está aí e precisa ser cumprida. A execução plena desse aparato regulatório possibilitará além da acessibilidade dos deficientes aos espaços urbanos, contribuirá para a mudança da percepção distorcida que parte da sociedade possui sobre as pessoas com deficiência. Conhecer e entender essa realidade é apenas o primeiro passo de um processo de transformação e de mudança das trevas para a luz.

\section{Considerações finais}

O objetivo deste artigo foi descrever a percepção dos deficientes visuais sobre as condições de acessibilidade na cidade de Manaus. Os resultados dos dados coletados em uma pesquisa qualitativa realizada através de entrevistas com roteiro semi-estruturado com seis deficientes visuais moradores da cidade de Manaus revelou que a falta da visão não é o principal problema no cotidiano dessas pessoas e nem tão pouco representa um obstáculo para que tenham uma vida normal, para que possam estudar, trabalhar e desfrutar momentos de lazer.

A pesquisa evidencia os avanços significativos na legislação brasileira sobre a questão da acessibilidade o que possibilitou uma mudança na forma de pensar e de planejar a acessibilidade nos espaços urbanos, deixando de lado a tradicional postura paternalista e assistencialista para uma visão estratégica para a promoção dos direitos e a integração das pessoas com deficiências na sociedade.

No entanto, os resultados das entrevistas apontam o descumprimento quase que total da legislação segundo a percepção dos entrevistados. 0 papel das associações e entidades que representam os deficientes visuais é apontado como um meio para exercer pressão e cobrar a quem de direito o cumprimento das leis que amparam o direito de ir e vir dos deficientes visuais.

No que tange a adaptabilidade dos espaços urbanos, todos os entrevistados foram unânimes em afirmar que a cidade de Manaus não foi pensada para atender as necessidades das pessoas que possuem deficiência visual. A cidade não possui áreas de circulação adequadas e livres de obstáculos, que ofereçam conforto e segurança, não possui mapas táteis e nem tão pouco pisos táteis que sinalizam os locais apropriados para circulação ou locais que possam afetar a integridade física dos deficientes visuais.

Faz-se necessário repensar os espaços urbanos e as edificações para tornar o ambiente mais 
propício e perceptível para uma pessoa com deficiência visual, o ambiente deve prover recursos que potencializem os sentidos remanescentes dessas pessoas para que possibilite a sua interação com o ambiente através das sensações. Vale lembrar que a audição e o olfato também contribuem para o processo de comunicação e de locomoção dos deficientes visuais. 0 espaço constituído das cidades deve ser planejado, organizado e pensado para que a pessoa com deficiência visual possa se sentir integrada a sociedade.

Outro ponto a ser destacado é o aumento da conscientização das pessoas com deficiência visual quanto aos seus direitos e ao esforço que vem sendo desempenhado pela efetivação dos mesmos, seja através de campanhas se sensibilização, ações de fiscalização e pelo esforço das entidades que representam essas pessoas.

No contexto da sociedade brasileira, caracterizada por intensa desigualdade social, as conquistas obtidas pelos deficientes visuais, nos últimos anos, ainda é seletiva, ou seja, quem possui melhores condições físicas, sociais e econômicas usufruem da máxima inclusão. Quem não possui essas condições, continua excluído e marginalizado.

Os resultados da pesquisa apontam para uma reflexão sobre a necessidade de mudar a postura da sociedade e da forma de conceber e adequar os espaços da cidade para essa parcela significativa da população. A cidade deve ser pensada e concebida para todos, independentemente das condições físicas, sociais ou econômicas das pessoas que a habitam. Para quem não vê a luz, à cidade não pode ser a escuridão. Esse é um ponto a ser repensado.

\section{Referências}

ABNT NBR 9050. Acessibilidade a edificações, mobiliário, espaços e equipamentos urbanos. Segunda edição, 2004.

AMAZONAS. Secretaria de Estado de Planejamento e Desenvolvimento Econômico. Perfil Econômico dos Municípios do Estado do Amazonas. Manaus: SEPLAN, 2010.

AMIRALIAN, M. L. T. M. Compreendendo o Cego: uma visão psicanalítica da cegueira por meio de desenhos-estórias. São Paulo: Casa do Psicólogo, 1997.

BARDIN, L. Análise de Conteúdo. 3. ed. Lisboa: Edições 70, 2004.

\section{BARROS, I. O. R.; COSTA, E. G. Matraca: Ferramenta Computacional para}

Auxílio a Deficientes Visuais no Uso do Computador. Disponível em <<http://www.enapet.ufsc.br/anais/MATRACA_FERRAMENTACOMPUUTACIONA L_PARA_AUXILIO_A_DEFICIENTES_VISUAIS_NO_USO_DO_COMPUTADO R.pdf $>>$, Outubro, 2006. Acesso em 29/11/2012 às 09h45min.

BAUER, M. W. Análise de conteúdo clássica: uma revisão. In: BAUER, M. W.; GASKELL, G. Pesquisa qualitativa com texto, imagem e som: um manual prático. Tradução de Pedrinho A. Guareschi. Petrópolis: Vozes, 2002. p. 189-217.

BERNARDI, N.; KOWALTOWSKI, D. C. C. K. Reflexões sobre a Aplicação dos Conceitos do Desenho Universal no Processo de Projeto de Arquitetura. Anais... Encontro Nacional sobre Conforto no Ambiente Construído (ENCAD) - Encontro Latino-americano sobre Conforto no Ambiente Construído (ELACAC), Maceio-AL, 2005, 9p.

BLANCO, M. A. 0 Conforto Luminoso como fator de Inclusão Escolar do Portador de Baixa Visão nas Escolas Públicas Regulares do Distrito Federal. 2007. 255 f. Dissertação 
(Mestrado em Arquitetura e Urbanismo) - Universidade de Brasília, Faculdade de Arquitetura e Urbanismo, Brasília/DF, 2007.

BORGES, J. A. DOS VOX: Um Novo Acesso dos Cegos à Cultura e ao Trabalho. Maio, 1996. Disponível em < http://www.ibcnet.org.br>. Acesso em 29/11/2012 às 10h30min.

BRASIL. Presidência da República - Casa Civil. Lei Federal No 7.405, de 12 de Novembro de 1985. Disponível em 《< http://www.planalto.gov.br/ccivil 03/leis/1980-1988/L7405.htm $>>$ Acesso em 28/11/2012 às 22h25min.

Constituição Federal de 1988. Disponível em $<$ http://www.senado.gov.br/legislacao/const/>> Acesso em 28/11/2012 às 21h58minh.

Presidência da República - Casa Civil. Decreto No 7.053, de 24 de Outubro de 1989. Disponível em $\quad<\quad$ http://www.planalto.gov.br/ccivil 03/Ato20072010/2009/Decreto/D7053.htm>> Acesso em 28/11/2012 às 22h15min.

Câmara dos Deputados. Decreto No 3.298, de 21 de Dezembro de 1999. Disponível em < $\quad$ http://www2.camara.leg.br/legin/fed/decret/1999/decreto-3298-20-dezembro-1999367725-norma-pe.html >> Acesso em 28/11/2012 as 22h05min.

Presidência da República - Casa Civil. Lei Federal No 10.098, de 19 de Dezembro de 2000. Disponível em << http://www.planalto.gov.br/ccivil 03/leis/L10098.htm $>>$ Acesso em 28/11/2012 às 22h34min.

.Ministério da Justiça. Convenções Ratificadas pelo Brasil, no Âmbito do Sistema ONU, até 2008. Disponível em $<<$

http://portal.mj.gov.br/sedh/11cndh/site/pndh/sis int/onu/convencoes/Convencoes, $\% 20$ trat ados $\% 20 \mathrm{e} \% 20$ pactos $\% 20$ ratificados $\% 20$ pelo\%20Brasil.pdf $>>$ Acesso em 28/11/2012 às $09 \mathrm{~h} 15 \mathrm{minh}$.

- Coordenadoria Nacional para Integração da Pessoa Portadora de Deficiência. Acessibilidade. Brasília, Secretaria Especial dos Direitos Humanos, 2008.

Instituto Brasileiro de Geografia e Estatística. Censo 2010. Disponível em $<$ http://www.ibge.gov.br >> Acesso em 28/11/2012 às 13h56minh.

CAMBIACHI, S. Desenho Universal: métodos e técnicas para arquitetos e urbanistas. São Paulo: Editora SENAC, 2007.

CAMPOS, P. M. X. Deficiência e Preconceito: a visão do deficiente. 2008. 91 f. Dissertação (Mestrado em Educação) - Universidade de Brasília, Faculdade de Educação, Brasília/DF, 2008.

CARVALHO, J. O. F. O Papel da Interação Humano-Computador na Inclusão Digital. Revista Transinformação, Campinas, v.15, n.3, 2003, p.75-89, set./dez.

CASELLI, B. C. A. Acesso à Informação Digital por Portadores de Necessidades Especiais Visuais: estudo de caso do Telecentro Acessível de Taguatinga. 2007. 107 f. Dissertação (Mestrado em Ciência da Informação) - Universidade de Brasília, Faculdade de Economia, Administração, Contabilidade e Ciência da Informação e Documentação (FACE), Departamento da Informação e Documentação, Brasília/DF, 2007. 
CHAGAS, A. M. R. Avanços e Impedimentos para a Construção de uma Política Social para Pessoas com Deficiência. 2006. 114 f. Dissertação (Mestrado em Política Social) Universidade de Brasília, Departamento de Serviço Social, Brasília/DF, 2006.

COOPER, D. R.; SCHINDLER, P. S. Métodos de Pesquisa em Administração. 7. ed. Porto Alegre: Bookman, 2003.

DAVIDOFF, L. Introdução à Psicologia. 3ª ed. São Paulo: Makron Books, 2001.

DENZIN, N. K; LINCOLN, I. S. Introdução: a disciplina e pratica da pesquisa qualitativa. In: Planejamento da pesquisa qualitativa: Teorias e abordagens. 2. ed. Porto Alegre: Artmed Bookman, 2006.

GARCIA, Etelvina. Modelo de desenvolvimento da Zona Franca de Manaus: história, conquistas e desafios. 2a. Ed. Manaus, Norma Editora: 2004.

LEÃO, J. F. M. C. Identificação, Seleção e Caracterização de Espécies Vegetais Destinadas à Instalação de Jardins Sensoriais para Portadores de Deficiência Visual. 2007. 133 p. Tese (Doutorado em Agronomia) - Escola Superior de Agricultura Luiz de Queiroz, Piracicaba/SP, 2007.

LINHARES, R. M. Contribuições da Telenovela à Inclusão Social de Alunos com Deficiência: um estudo de caso a partir da recepção da telenovela América. 2008. 140 f. Dissertação (Mestrado em Educação) - Universidade de Brasília, Faculdade de Educação, Brasília/DF, 2008.

MENDES, A. B. Avaliação das Condições de Acessibilidade para Pessoas com Deficiência Visual em Edificações em Brasília - Estudos de Casos. 2009. 288 p. Dissertação (Mestrado em Arquitetura e Urbanismo) - Faculdade de Arquitetura e Urbanismo da Universidade de Brasília, Brasília/DF, 2009.

MORAIS, E. M. S. Sorobã: suas implicações e possibilidades na construção do número e no processo operatório do aluno com deficiência visual. 2008. 160 f. Dissertação (Mestrado em Educação) - Universidade de Brasília, Faculdade de Educação, Brasília/DF, 2008.

NASCIMENTO, R. M. M. Equivalência de Estímulos Auditivos e Táteis em Crianças com Deficiência visual: ensino de letras do Alfabeto Braille e Romano. 2007. 65 f. Dissertação (Mestrado em Psicologia) - Universidade de Brasília, Instituto de Psicologia, Brasília/DF, 2007.

NORMANN, A. F. M. Acessibilidade: os desafios ergonômicos à aplicação das normas de proteção do trabalho de pessoas portadoras de deficiência - PPD's. 2004. 154 p.

Dissertação (Mestrado em Profissional em Engenharia de Produção) - Universidade Federal do Rio Grande do Sul, Porto Alegre/RS, 2004.

OLIVEIRA, A. S.; CARVALHO, L. Deficiência Visual: mais sensível que um olhar. Colloquium Humanarum, v. 3, n. 2, Dez. 2005, p. 27-38.

PERSON, E. Espaços de Permanência e Passagem: contribuição para elaboração de diretrizes ambientais e de acessibilidade para o desenho urbano. 2006. 167 f. Dissertação (Mestrado em Arquitetura e Urbanismo) - Universidade de Brasília, Faculdade de Arquitetura e Urbanismo, Brasília/DF, 2006.

REY, F. G. Pesquisa Qualitativa e Subjetividade: Os processos de construção da informação. São Paulo: Thompson Learning: São Paulo, 2005. 
RODRIGUES, M. S. P.; LEOPARDI, M. T. 0 Método de Análise de Conteúdo: uma versão para enfermeiros. Fortaleza: Fundação Cearense de Pesquisa e Cultura, 1999.

ROSADAS, S. C. Educação, Teorias e Práticas Pedagógicas de Deficiência Mental. Vitória: UFES, 1994, p. 9-35.

SARRAF, V. P. 0 Conceito de Acessibilidade Ganha Força entre os Museus Brasileiros. Rev. Cidadania. Ano 5, №. 40. Bunge. São Paulo, 2007.

THIOLLENT, M. Pesquisa-ação nas organizações. São Paulo: Atlas, 1997.

VALA, J. A Análise de Conteúdo. In: SILVA, A.S.; PINTO, J. M. Metodologia das Ciências Sociais. 12 ed. Porto: Edições Afrontamento, 2003. p. 101-128. 